\title{
HISTÓRIA E MEMÓRIA DA ESCOLA FAMÍLIA AGRÍCOLA DE ELISEU MARTINS (EFAEM) (PI)
}

\author{
History and memory of Eliseu Martins Family Agricultural School (EFAEM) (PI)
}

Pâmela Torres Michelette ${ }^{1}$

Maria Francisca Brasileiro Costa Barbosa de Lima²

\begin{abstract}
RESUMO: Neste artigo, buscaremos reconstruir parte da história e da memória da Escola Família Agrícola de Eliseu Martins (EFAEM), objetivando relatar o processo histórico da instituição, com ênfase no seu processo histórico de construção. Esse trabalho contribui para a reconstrução da história e memória da EFA e também, de seu fortalecimento na região. Utilizamos como metodologia, a história oral, por meio de entrevistas abertas e dialogadas, que permitiram aos entrevistados narrar suas experiências no processo de criação desse espaço de ensino, bem como, eles compreenderam o trabalho que ali foi implantado pelo Pe. Cícero de Moura Filho. A memória e a história estão interligadas, ambas são importantes para entender o tempo presente. Rememorar a história dessa escola, possibilita-nos uma reflexão da história da Pedagogia da Alternância e sua importância para o papel que as EFAs têm no sul do Piauí, destacando os principais acontecimentos, curiosidades, relacionando o passado com o momento histórico vivido.
\end{abstract}

Palavras-chaves: Memória e História. EFAEM. Reconstituição.

ABSTRACT: In this article, we seek to reconstruct part of the history and memory of the Escola Familia Agrícola de Eliseu Martins (EFAEM), aiming to report on the historical process of the institution, with emphasis on its historical construction process. This work contributes to the reconstruction of the history and memory of EFA and also of its strengthening in the region. We used oral history as a methodology, through open and dialogued interviews, which allowed the interviewees to narrate their experiences in the process of creating this teaching space, as well as, they understood the work that was implemented there by Fr. Cícero de Moura Filho. Memory and history are interconnected, both are important to understand the present time. Recalling the history of this school, allows us to reflect on the history of Pedagogy of Alternation and its importance for the role that EFAs have in the south of Piauí, highlighting the main events, curiosities, relating the past to the lived historical moment.

Keywords: History and memory. EFAEM. Reconstitution.

\section{CONSIDERAÇÕES INICIAIS}

\footnotetext{
${ }^{1}$ Doutora em História pela Universidade Estadual Paulista Júlio de Mesquita Filho (UNESP). Professora do curso de Licenciatura em Educação do Campo da Universidade Federal do Piauí (UFPI), Campus Professora Cinobelina Elvas (CPCE), em Bom Jesus (PI). E-mail: pamelamichelette@yahoo.com.br

2 Atualmente está como professora substituta da Universidade Federal do Piauí (UFPI), no curso de Licenciatura em Educação do Campo (LEdoC). Licenciada em Pedagogia (FTB) e em Educação do Campo (UFPI). Mestranda em Educação pela UFPI. Atuou na gestão da EFAEM, nas funções de diretora (professora e coordenadora pedagógica). E-mail: pretaguadalupe@,hotmail.com
} 
O resgate da história da Escola Família Agrícola de Eliseu Martins (EFAEM) aconteceu por meio de entrevistas abertas e dialogadas, que agregou valores através de estudos e abordagens, que permitiram-nos retomar a subjetividade e a realidade, através da reconstituição das lembranças da EFA de forma significativa ${ }^{3}$. A EFAEM, foi a primeira Escola Família da região do Vale do Gurguéia a ser implantada na região localizada na zona rural de Eliseu Martins (PI), comunidade Cabeça D’agua, Rodovia PI 141, Km 2.

A memória e a história estão interligadas e são relevantes para entender o tempo presente e, a utilização dessas ferramentas, como fonte de pesquisa foi de grande importância no processo de edificação de parte desse passado, através de reflexões, relatos sobre a Pedagogia da Alternância e sobre o processo de construção e solidificação da EFA.

Ferro (1996) nos traz importante reflexão nesse sentido, pois afirma que a história da educação de um povo é importante e necessária para a compreensão de sua própria formação e identidade cultural, assim como para a percepção do modo de ser, pensar e agir, enfim, das características próprias desse povo.

A história dessa escola é importante, pois ela é uma espécie de base da educação local, alicerce para o homem do campo. Por meio dela, ocorre o acolhimento, a integração, a união, o compartilhamento, a visitação, a formação, a edificação e a transformação dos sujeitos. A EFAEM significa muito para as famílias da região onde ela se estabeleceu, possibilitando o ingresso de muitos filhos de camponeses em um ensino diferenciado. Ensino este, que foi pensado para o fortalecimento do homem do campo no campo.

As considerações que podemos apresentar aqui, com base na pesquisa e na experiência com esse espaço de ensino, demonstram que essa trajetória não teve um percurso simples e fácil. Ela esteve envolta de muitas dificuldades e desafios, um dos maiores deles, foi a instabilidade. $\mathrm{O}$ que queremos dizer que esse é um processo de resistência e resiliência. Com este trabalho, enquanto monitora (Maria Brasileiro) de uma Escola Família, passamos por várias experiências, a mais recente delas foi assumir a direção da EFA, onde através da aplicabilidade dos instrumentos pedagógicos da Pedagogia da Alternância, juntamente com todo corpo docente da escola, procuramos valorizar os espaços formativos que nossos educandos estão inseridos. Por outro lado, as ações do nosso Plano de Formação podem ser rompidas, devido à instabilidade no emprego, sem durabilidade.

Um dos objetivos deste artigo é dar voz ao relato daqueles que, por muito tempo foram silenciados e esquecidos. Neste trabalho, eles foram lembrados e valorizados, fazendo também,

\footnotetext{
${ }^{3}$ Essa pesquisa surgiu do TCC defendido pela Maria Francisca B. C. B. de Lima em 2018, no curso da LEdoC, orientado pela profa. Pâmela T. Michelette.
} 
com que as demais EFAs se sintam representadas, alcançando o reconhecimento do trabalho realizado pelas famílias organizadas através da associação e de equipe de monitores.

Dessa forma, para Benjamin (1993), a memória e a narração integram-se como uma possibilidade de romper com a linearidade do cotidiano. Com uma interação entre os espaços e os tempos que constituíram o processo histórico da EFA, foi possível ir além do convencional para contar uma história, quebrando paradigmas, enfrentando obstáculos e desafios durante o percurso desse conhecimento.

O trabalho de reconstituição da memória da EFAEM servirá de norte para outros pesquisadores, pois encontrará características únicas da Instituição, como também, terá acesso a elementos que se assemelham a história de outras EFAs. Rememorar essas lembranças trouxe uma compreensão maior acerca dessa pedagogia e do trabalho da escola realizado na região.

Segundo Freitas (2002), a memória se liga mais a imaginação, ao vivido, enquanto que a história procura refletir sobre essas vivências. Recordar a vivência é o que fomenta esse processo de reconstrução. A história oral nos possibilitou estabelecer uma relação direta com o vivido (MEIHY; HOLANDA, 2007). Assim, por meio da história oral, se estabeleceu uma relação, através do procedimento de sintetização de elementos que constituem a mesma, que nos nortearam no processo de descoberta, servindo de base metodológica para a realização das entrevistas.

Dessa forma, as entrevistas realizadas estabeleceram uma relação com o vivido, trazendo o passado para ser recordado no presente. Essa relação entre o passado e o presente, enfatizando as referências, as especificidades que as constituem, tendo em vista que as EFAs são fruto da luta de camponeses que se organizaram na busca de uma educação diferenciada para seus filhos.

\section{HISTÓRIA E MEMÓRIA}

A recordação da memória para a transmissão do vivido por meio de narrativas, tem como método, a história oral de vida. Contudo, a memória presente nos relatos orais não é sinônimo de história oral. A passagem daquela etapa para esta se dá por meio da aplicação rigorosa do método, que é um recurso moderno, usado para elaboração de documentos, arquivamentos e estudos referentes à experiência social de pessoas e de grupos (MEIHY, 2005).

A história oral é um instrumento importante na construção da pesquisa, pois, além de analisar documentos escritos no trabalho de pesquisa, pode-se recordar o vivido. A história oral apresenta uma perspectiva interessante no processo de constituição da memória humana, como destaca Alberti (1990, p. 04): 
[...] a história oral apenas pode ser empregada em pesquisas sobre temas contemporâneos, ocorridos em um passado não muito remoto, isto é, que a memória dos seres humanos alcance, para que se possa entrevistar pessoas que dele participaram, seja como atores, seja como testemunhas. É claro que, com o passar do tempo, as entrevistas assim produzidas poderão servir de fontes de consulta para pesquisas sobre temas não contemporâneos.

Nesse viés, a história oral está relacionada ao ato de rememorar. Segundo Silva (2012), a história oral veio abrir espaços, vez e vOz ao sujeito que recorda, através da recordação das experiências vivenciadas no meio social, tornando-os sujeitos ativos no processo de reconstrução da história. Permite aos sujeitos da história expressar valores construídos ao longo de suas vidas, repensarem e refletirem as suas histórias. A recordação do vivido. É o processo de reconstituição da memória humana, que facilita a compreensão de aspectos da vivência individual e social.

A memória, entendida como a presença do passado, é também "uma representação seletiva de um passado, um passado que nunca é aquele do indivíduo somente, mas de um indivíduo inserido num contexto familiar, social, nacional" (ROUSSO, 1996, p. 94). A memória é uma abordagem significativa da pesquisa, pois apresenta uma dimensão da humanidade, reconstruída a partir das narrativas ao longo do processo de rememoração da história de determinado grupo.

Dessa forma, a história oral destaca-se porque traz o conhecimento relatado através de experiências humanas, que são transformadas em documentos, como afirma Meihy (2005, p. 17):

História oral é um conjunto de procedimentos que se iniciam com a elaboração de um projeto e que continuam com a definição de um grupo de pessoas a ser entrevistadas. O projeto prevê: planejamento da condução das gravações; transcrição; conferência da fita com o texto; autorização para o uso; arquivamento e, sempre que possível publicação dos resultados.

Assim, a história oral não pode ser realizada sem uma preparação, visto que essa é uma das características mais marcantes desse método, que trabalha com a subjetividade dos sujeitos individuais e coletivos, a fim de entender o tempo presente representado a partir de fragmentos do passado.

Dessa maneira, Thompson (1992) defende que a história oral proporciona relatos da história, dando vez e voz aqueles que são esquecidos, dando oportunidade de recordar sua história. História, tempo e memória caminham lado a lado e a relação entre eles facilita o ato de rememorar, através da reconstrução da história do vivido.

Ainda nessa questão, para Delgado (2006, p. 17), “o tempo da memória ultrapassa o tempo de vida individual e encontra-se com o tempo da história, visto que se nutre de lembranças, de tradições, de histórias escutadas e registradas". É através desses fragmentos do passado, que 
iremos entender o presente, dialogando com esses vestígios, inserindo os registros da participação humana, no nosso caso, a EFA de Eliseu Martins (PI).

Desenvolver um trabalho como esse, nos possibilitou conhecer diferentes visões e pontos de vistas, reconhecer o local de fala de cada sujeito, aprender a cultivar a flexibilidade e a escuta foi fundamental nesse processo. Com essa estratégia de trabalho, buscamos contemplar e adaptar-se às condições do meio pesquisado:

A história oral tem sido outro recurso valioso como fonte e instrumental, principalmente no que se refere à história menos remota. Este recurso tem, entre outros, a vantagem de poder confrontar as informações documentais com a visão das pessoas-fontes sobre as experiências vividas, ou visões diferentes de atores educacionais distintos. (FERRO, 1996, p. 173)

É importante fazer essa relação de confronto de informações, cabendo ao pesquisador tal tarefa, em virtude de manter a maior neutralidade diante dos fatos, respeitando os entrevistados e suas especificidades. Dessa maneira, a história oral é fundamental, pois constitui uma história que representa os sujeitos, através do espaço e do tempo. Para Meihy; Holanda (2007, p. 17), a:

História oral é um recurso moderno usado para elaboração de registros, documentos, arquivamento e estudos referentes à experiência social de pesquisa e de grupos. Ela é sempre uma história do tempo presente e também reconhecida como história viva.

A história oral produz relatos orais, que são narrativas de memórias fundantes da construção da teoria, no que se refere ao reconhecimento histórico do vivido. Essas, por sua vez, são narrativas de identidade, na medida em que o sujeito não apenas mostra como ele vê a si mesmo e o mundo, mas como sujeito de um coletivo.

Ao considerarmos as memórias como fontes da história, estamos levando em conta, um sentido específico de memória, o que exige uma reflexão sobre a sua natureza. Os autores James Fentress e Chris Wickham (1992) analisam essa questão, afirmando que a memória são documentos localizados na cabeça das pessoas, que não são arquivos públicos. As memórias estão relacionadas a processos de subjetivação, que incluem sensações e imagens mentais que estão ancoradas em espaços e lugares nos quais circulamos, em grupos sociais de diferentes tipos. Quem recorda são os indivíduos e estas experiências fazem parte de uma memória social.

\section{PEDAGOGIA DA ALTERNÂNCIA: UM SONHO POSSÍVEL}


Os desafios enfrentados para garantir uma educação de qualidade no campo, fizeram surgir novas experiências, as quais possibilitaram alternativas pensadas e geridas pelos camponeses, movimentos sociais do campo e instituições religiosas, que se constituem como uma nova possibilidade de ensino por meio da alternância.

A Pedagogia da Alternância é constituída de momentos alternados de vivência e de estudo na escola, na família e na comunidade. Nesse sentido, a alternância passa a exercer uma função metodológica e pedagógica no processo formativo dos educandos. As EFAs têm a preocupação de fazer com que a alternância se dê na própria família e no espaço rural do qual os sujeitos fazem parte. Para que a formação dos jovens e adolescentes do campo aconteça, utiliza-se de espaços e tempos diferentes, que são divididos entre o meio socioprofissional (família, comunidade e trabalho) e o espaço escolar em regime de internato, com ênfase na formação integral do aluno e o desenvolvimento local. De acordo com Queiroz (2004, p. 103):

O grande desafio para a escola da alternância é articular essas relações com o saber na integração realidade da escola e realidade do trabalho. Pois não se trata apenas de articular os dois espaços, dois lugares diferentes. Mas é necessário "colocar em coerência duas relações com o saber num projeto de formação". E para isso se faz necessário "uma pedagogia do saber partilhado" que reconhecendo as diferenças e as contradições às torne formadoras.

É uma pedagogia que estabelece, através de sua aplicabilidade, uma relação que articule e integre o sistema educacional, por meio de uma construção coletiva e participativa do conhecimento, que ocorre em diferentes espaços nos quais os alternantes estão inseridos.

Segundo Caldart (2008), a Pedagogia da Alternância dá-se como um desejo de não cortar as raízes com o campo, pois busca integrar escola, família e comunidade. De acordo com a autora, a Pedagogia da Alternância foi pensada em dois momentos distintos e, ao mesmo tempo, complementares, sendo: o tempo escola e o tempo comunidade, ou sessão escolar e sessão familiar. Esse regime alterna tempos e espaços, promovendo uma formação diferenciada, onde o alternante é o protagonista do seu próprio conhecimento.

As EFAs surgiram na década de 30 na França. A Europa, nesse período (1920-1939), sofria uma transformação importante, principalmente na agricultura, com o processo de mecanização. Os mercados da carne, do leite e do trigo passavam por uma grave crise econômica, e esses eventos acarretaram em reflexões por parte dos agricultores sobre a situação pela qual estavam passando. Por isso, em setembro de 1935, numa pequena aldeia do interior da França, o presidente do Sindicato Rural Jean Peyrat e o Pe. Granerau, grande incentivador dos movimentos sociais na região, decidiram criar uma escola com um caráter diferenciado para os estudantes locais, que foi chamada Maisons Familiales Rurales (MFR) (FERRO, 1996). 
Essas Maisons Familiales, aqui no Brasil, surgiram com o nome de Escola Família Agrícola. No final dos anos 60, no Estado do Espírito Santo, a iniciativa chegou por meio de uma missão jesuíta, sob a liderança do Pe. italiano Humberto Pietrogrande, no dia 09 de março de 1969. Assim, as Escolas-Família-Agrícola de Olivânia, localizada no município de Anchieta; e a de Alfredo Chaves, receberam seus primeiros alunos. Em pouco tempo, esse modelo de escola espalhou-se por 20 estados do país.

No que tange ao Piaú, as EFAs surgiram em 1985, também pela iniciativa do Pe. Humberto Pietrogrande, que foi transferido do Espírito Santo para o Piauí, através da missão jesuíta. Em solo piauiense, criou as primeiras EFAs e deu início a Fundação Padre Antônio Dante Civiero (FUNACI) (1989) ${ }^{4}$. Essa entidade foi responsável pelos cinco primeiros anos das EFAs no Estado. A partir da fundação dessas instituições de ensino, surgiu a necessidade de uma junta que pudesse dialogar em conjunto sobre as questões das EFAs abertas. Com base nesse contexto, foi fundada a Associação das Escolas Famílias Agrícolas do Piauí (AEFAPI), criada em 2004, sob a direção, inicialmente, de João Emílio Lopes Pinheiro. A partir dessa experiência, a EFAEM foi, primeiramente, idealizada em 2005 e inaugurada em 14 de abril de 2006, sendo a primeira EFA na região do Vale do Gurguéia.

A formação em alternância requer uma organização de atividades e instrumentos pedagógicos específicos para articular os tempos e espaços, a fim de associar e colocar em sinergia as dimensões profissionais e gerais, bem como, aperfeiçoar as aprendizagens. A alternância ocorre com a presença dos alunos entre a escola e a comunidade como concepção de diálogo educativo. Segundo Palitot (2007), a Pedagogia da Alternância utiliza-se de instrumentos pedagógicos próprios, busca um processo de formação docente diferenciado apropriado e visa o fortalecimento da relação escola/comunidade na gestão, organização e coordenação da proposta educacional.

Dessa forma, a Pedagogia da Alternância integra e valoriza as especificidades dos educandos, levando em conta seus modos de vida e seus desenvolvimentos no meio ao qual estão inseridos. Assim, a alternância possibilita um diálogo que é fundamental para a formação do ser humano, conforme afirma Silva (2007, p. 58):

O diálogo entre o mundo da escola e o mundo da vida, a teoria e a prática, o universal e o específico, enfim uma escola que, enraizada na cultura do campo, contribui para a melhoria nas condições de vida e de trabalho dos agricultores (as), e principalmente numa formação humana e criativa da pessoa.

\footnotetext{
${ }^{4}$ Entidade filantrópica, que nasceu inspirada nos princípios da Doutrina Social da Igreja e que tem como princípios o serviço da fé e da formação da justiça, com os mesmos fundamentos norteadores do Movimento de Educação Promocional do Espírito Santo (MEPES), ação pioneira da Pedagogia da Alternância e que possui a mesma fonte inspiradora, os mesmos objetivos e setores de atuação relacionando vulnerabilidade socioeconômica dos menos favorecidos, desenvolvendo trabalhos na área da educação, saúde, inclusão social e agricultura familiar.
} 
O trabalho realizado através das EFAs visa também, o desenvolvimento social, econômico, cultura, profissional dos alternantes. "A história das Escolas-Famílias é antes de tudo a história de uma ideia, ou melhor, a história de uma convicção que permanece viva ainda hoje" (NOSELLA, 2012, p. 45). A filosofia das EFAs é contra hegemônica, pois vivencia a realidade do aluno, causando, vez por outra, desconfiança e incômodo para a política educacional tradicional implantada.

Nas EFAs, a família e a comunidade são destacadas como ambientes de origem de aprendizagem, bem como, espaços de constituição de saberes de diversos sujeitos, a escola, por sua vez, como o agente integrador de conhecimentos. Segundo Palitot (2007, p. 18):

Os instrumentos pedagógicos da Alternância possibilitam às escolas que a utilizam realizar a educação nas três dimensões possíveis, que são: a educação formal (escola), a educação não-formal (práticas educativas realizadas na comunidade e na sociedade) e a educação informal (família).

Uma das figuras de destaque desse formato de ensino é o monitor, que tem um papel importante no processo de ensino e aprendizagem da Pedagogia da Alternância, pois cabe a este profissional acompanhar, animar, dinamizar todas as atividades a serem desenvolvidas nas EFAs.

Por estes aspectos, a Pedagogia da Alternância da condição e contribui para formação de jovens participativos, podendo ser uma alternativa para a educação do campo, uma vez que "É também o palco de uma vida social no meio de um grupo de vida". (GIMONET, 2007, p. 140)

A metodologia de ensino da Pedagogia da Alternância propõe uma formação específica para os monitores promoverem uma maior interação entre a escola e as famílias. Através do Plano de Formação das EFAs é desenvolvido o processo de formação dos monitores, que ocorre por meio da formação inicial dos fundamentos teóricos, filosóficos e metodológicos da alternância, com o objetivo de promover a integração do monitor com o trabalho da escola e a vivenciar melhor a dinâmica da instituição, sobretudo, na utilização dos instrumentos pedagógicos da Pedagogia da Alternância. Paralela à formação inicial, acontece à formação continuada, que são momentos de estudos, debates, palestras e pesquisas sugeridas pelos monitores para o fortalecimento das ações desenvolvidas e o aperfeiçoamento da metodologia da EFA, com o propósito de caminharem conjuntamente.

A Pedagogia da Alternância é uma formação integral e transformadora do jovem rural e de seu meio. A escola e a família possibilitam o desenvolvimento dos pequenos agricultores em sua região. A Alternância visa a formação do jovem do campo no aspecto intelectual e profissional, 
tendo como princípio, uma abordagem metodológica que não nega a autonomia do sujeito, pois caracteriza-se pela ação-reflexão-ação.

\section{O SURGIMENTO DA EFAEM}

As informações acerca do surgimento da EFAEM têm como base, relatos documentais, experiências de trabalho e da vivência de atores da época da criação da escola e que ainda atuam na mesma. Como já mencionamos, a EFAEM foi planejada em 2005 pelo Pe. Cícero de Moura Filho, que buscou a ajuda de João Emílio, na época, Secretário Executivo da AEFAPI. No dia 26 de agosto de 2005, o padre juntamente com João Emílio, reuniram-se com os membros de alguns segmentos sociais da região, na igreja de São Bartolomeu às 15:00 horas, de acordo com D. Maria José Ferreira de Sousa (2018), uma liderança da Igreja Católica local. A primeira reunião teve considerável número de participantes de várias instituições locais. Os envolvidos estavam bastante otimistas com a proposta. A motivação e a receptividade por parte dos envolvidos foi rápida, já que, no dia seguinte, foi realizada a limpeza do local onde se estabeleceria a escola.

Uma das primeiras iniciativas foi a criação da Associação Escola Família Agrícola de Eliseu Martins, que teve como mantenedora a AEFAPI, que ofereceu toda autonomia para associação criar a escola. A princípio, o Pe. Cícero pensou em implantar a escola no município de Colônia do Gurguéia (PI), só que a proposta não interessou as autoridades locais, pois na cidade já existia um Centro de Formação. Como o padre trabalhava nas duas cidades, e, a partir de conversas com alguns moradores de Eliseu Martins (PI), lideranças sindicais, agricultores e representantes religiosos, deram início ao projeto de construção da EFA no munícipio.

A instituição foi constituída através da filantropia, os recursos utilizados foram de doações conseguidas pelo Pe. Cícero, em parceria com a AEFAPI, recursos esses que foram importantes para custear os materiais para a edificação da escola e parte da mão de obra.

Em 14 de abril de 2006, a escola recebeu sua primeira turma, composta por 35 alunos, dos quais tiveram muitas desistências. Houve muita descrença, desconfiança e desinformação por parte da população com relação a essa nova metodologia de ensino. Os desafios foram muitos, especialmente, na abertura da instituição, que começou a funcionar sem água encanada e sem energia, foi preciso contar com a sensibilidade de muitas pessoas que colaboraram com o projeto. Desde a inauguração da escola, as famílias passaram a contribuir com uma cesta básica na entrada de cada período de seus filhos matriculados. Por meio da associação, as famílias também contribuíam mensalmente com o valor correspondente a 1\% do salário mínimo, que foi definido em assembleia pela Associação. 
Segundo João Emílio Lemos Pinheiro (2018), Ex-Secretário da AEFAPI, a criação da EFAEM possibilitou a ideia de protagonismo, conduzindo as famílias a saírem da condição de subserviência, levantando-se para militância e para o enfrentamento da elite dominante, inclusive, pela gestão da Associação.

Figura 1: Mostra o terreno onde foi construída à escola para iniciar a construção

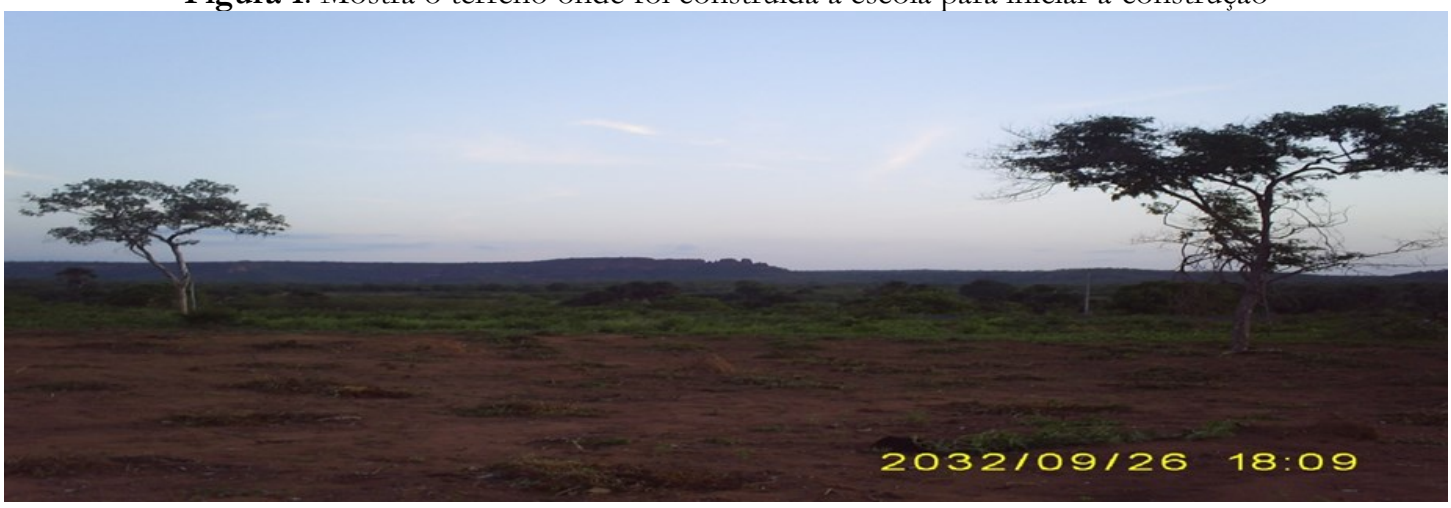

Fonte: Acervo fotográfico da EFAEM - ano 2005

De acordo com Eliseu Rodrigues Machado (2018), no início foi difícil encontrar alguém para trabalhar na edificação da escola. Mas, após o início das obras, houve a procura por muitas pessoas querendo trabalhar.

Figura 2: Representa o início da construção, estão presentes alguns pedreiros e o Pe. Cícero de Moura Filho

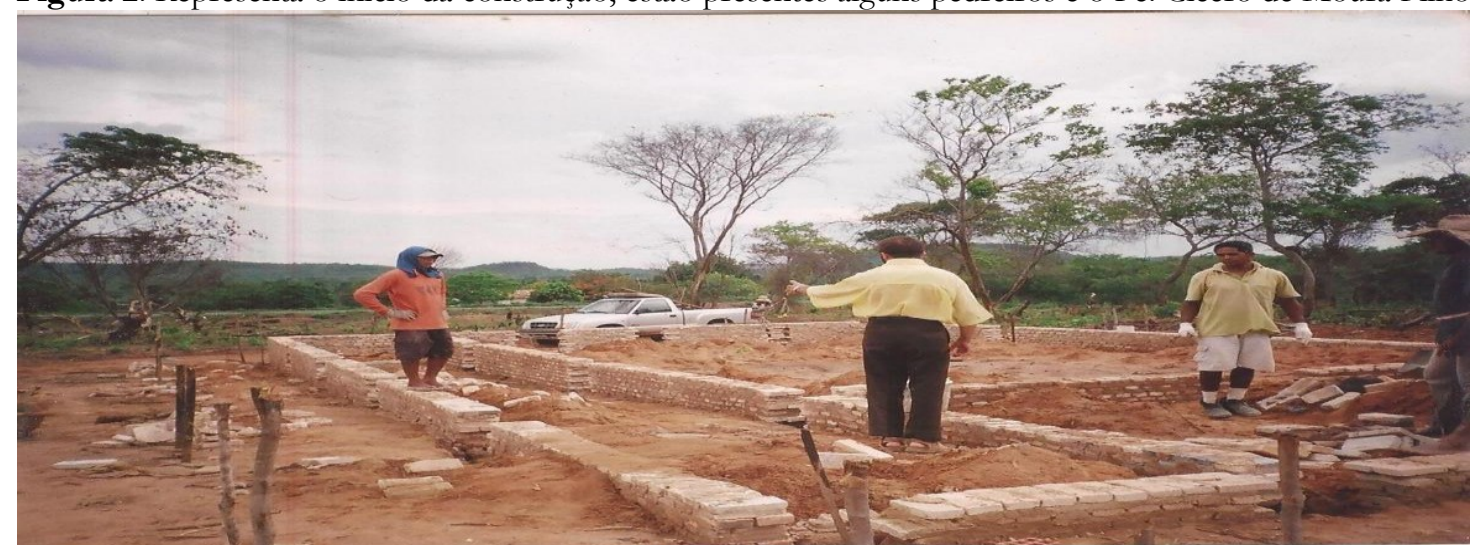

Fonte: Acervo fotográfico da EFAEM - ano 2005

Em 2006, a escola passou a funcionar em regime de alternância, com o objetivo de desenvolver trabalhos direcionados aos agricultores familiares da região e municípios vizinhos. O reconhecimento da escola propagou-se rapidamente, ganhando notoriedade na região, o que acarretou no seu desenvolvimento e perduração.

Como já mencionamos, a abertura da escola contou mais com a boa vontade dos integrantes do que com infraestrutura. Outras situações que exemplificam essa realidade, foi a falta de fogão para cozinhar, não se tinha ainda a autorização de funcionamento, não possuía um quadro 
efetivo de monitores. Os profissionais que atuaram, a princípio, eram cedidos pelo Estado ou pelo município, para complementarem suas cargas horárias. Com o funcionamento da escola, o Pe. Cícero assumiu a direção da EFA e contou com a colaboração da professora Adriana Moura, na função de secretária da escola.

Em 2010, houve o primeiro teste seletivo para escola. Nesse mesmo ano, a escola passou a ter sua própria equipe de monitores. A partir daí, foi possível adquirir maior autonomia nas ações e processos de aprendizagem desenvolvidos pela escola. A instituição recebeu alunos oriundos de vários municípios e localidades rurais das proximidades de Eliseu Martins (PI), Colônia do Gurguéia (PI), Manoel Emídio (PI), Alvorada do Gurguéia (PI) e Canto do Buriti (PI). Também, temos alunos de várias comunidades rurais de todos estes municípios citados.

Desde 2016 que as famílias não contribuem mais com a cesta básica, pois o Estado passou assumir essa despesa das EFAs e os nossos alunos também foram inseridos no Sistema de Ensino da Rede Estadual.

Atualmente, a escola encontra-se organizada da seguinte forma: a Associação, que é a mantenedora da escola, formada pelos pais, representados por um conselho que é composto pelo presidente, sendo a maior autoridade, de acordo com o regimento da escola, além do vicepresidente, secretária, tesoureira e outros conselheiros, totalizando 12 membros. Na parte pedagógica, existe, como nas outras escolas, a figura do diretor(a), secretária e supervisora e corpo docente, composto de 13 monitores. De 2006 até 2019 passaram pela associação da escola, quatro presidentes que foram eles:

$1^{\circ}$ - Francisco de Assis de Sousa Batista - passou por dois mandatos, de 2006 a 2010; foi um grande colaborador no processo de construção da escola, pai de dois egressos e morador da comunidade Chupeiro, zona rural do município de Eliseu Martins (PI).

$2^{\circ}$ - Domingos Barbosa de Lima - passou por dois mandatos, de 2011 a 2015; também contribui bastante com o crescimento da EFA. Pai de dois egressos, morador da Comunidade Angico Branco, zona rural do município de Eliseu Martins (PI).

$3^{\circ}$ - Francisco Carmino de Sousa Batista - cumpriu dois mandatos seguidos, fundando o segundo, em janeiro de 2019. O presidente falava a linguagem da escola, além de ser muito atuante. Em seu período de atuação, buscou sempre fazer o melhor pela EFAEM. Também, era pai de um egresso e morador da Comunidade Chupeiro, zona rural do município de Eliseu Martins (PI).

$4^{\circ}$ - Maria Ildeni Barbosa de Lima - iniciou seu mandato em janeiro de 2019, tem uma boa atuação junto às famílias, sempre desenvolvendo trabalhos junto à direção da escola e o conselho da associação de pais. Seu mandato finaliza em janeiro de 2021, podendo ser reeleita novamente. Mãe de aluna egressa, mora em Eliseu Martins (PI). 


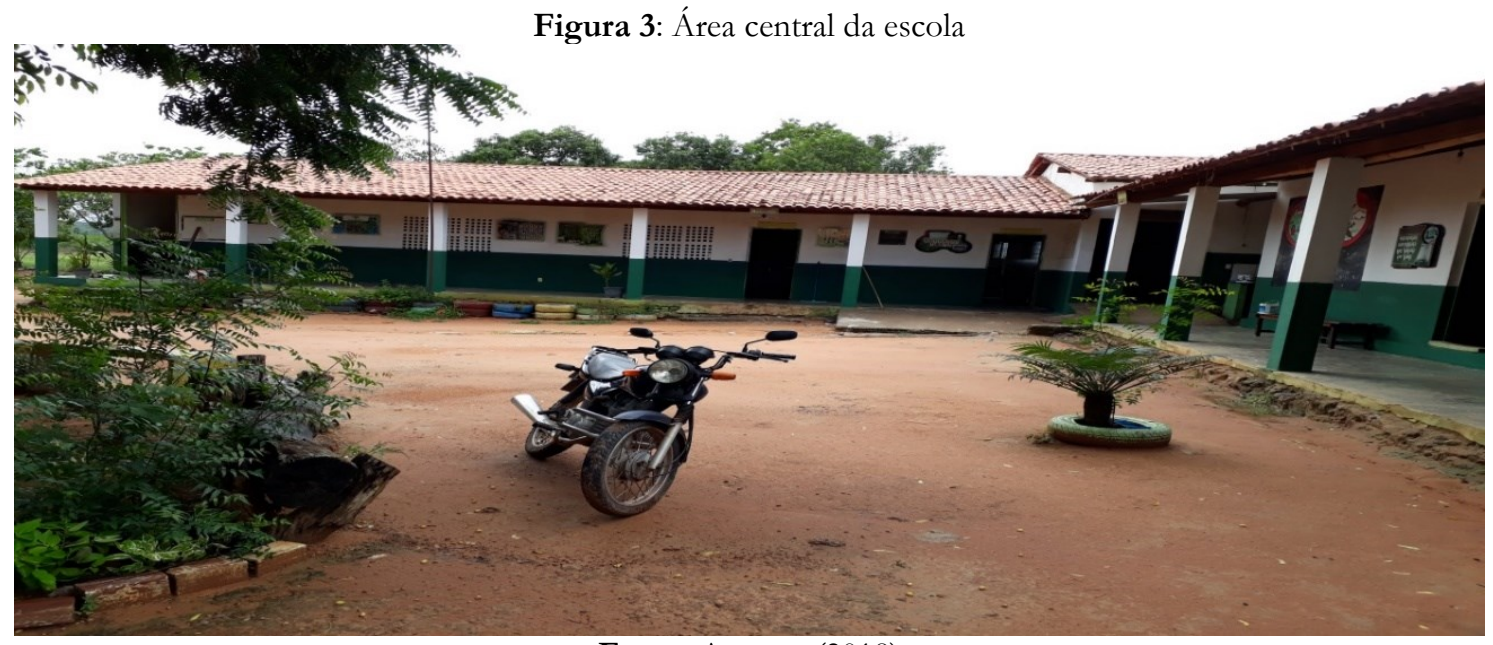

Fonte: Autoras (2018)

A estrutura da escola foi melhorando com o passar dos anos. Atualmente, possui um ambiente arborizado bastante agradável. Além de ter boas instalações e em bom estado de conservação.

Voltando para a método da alternância, a implantação dessa metodologia atua no desenvolvimento rural sustentável, através da formação dos jovens e da sistematização do conhecimento. O modelo de gestão da EFA é democrático e comunitário, condição fundamental para assegurar os princípios filosóficos e metodológicos de tal estrutura pedagógica.

Existe uma organização de ensino, que consiste em um sistema pedagógico, por meio do qual é desenvolvido o processo de ensino e aprendizagem, a partir da experiência e da realidade concreta dos educandos, onde o meio socioprofissional representa o eixo principal da proposta pedagógica. O método de ensino consiste na organização da formação em espaços e tempos diferenciados, alternando períodos no centro educativo e períodos no meio socioprofissional familiar, denominados Sessão Escolar e Sessão Familiar. A dinâmica da alternância se desenvolve em três momentos integrados, que conjugam um itinerário num processo de aprendizagem.

Através dessa sistematização, promove-se uma educação envolvendo as famílias, as comunidades e as entidades em um trabalho de promoção global do homem do campo. Utilizando como referenciais o Projeto Político-Pedagógico, o Plano de Curso, os Instrumentos Pedagógicos, o Plano de Formação por meio de ferramentas pedagógicas e a Pedagogia da Alternância que fundamenta a formação integral do educando, associada ao mundo do trabalho.

Dessa maneira, a partir das experiências dos educandos, a escola busca proporcionar aos jovens uma formação de qualidade, que lhes permita descobrir a sua vocação e desenvolver o seu projeto profissional ou projeto de vida, junto com suas famílias e no meio em que vivem, abrindo 
as possibilidades de inserção profissional e empreendedorismo, com sucesso e dignidade, como agente de transformação no meio rural.

A organização de uma EFA é bem mais complexa do que as escolas tradicionais. Um dos diferenciais que destacamos são as decisões tomadas comunitariamente em assembleias e reuniões do conselho. A eficácia da ação educativa da escola é assegurada no plano de formação desenvolvida com os monitores (formação inicial e continuada em Pedagogia da Alternância) e demais atores envolvidos no processo educativo, como: famílias, dirigentes de associações, diretores etc.

Com os anos, a escola foi expandindo sua estrutura, quadro de professores e alunos. Neste ano de 2020, a escola completou 14 anos, sendo possível observar alguns avanços e confiabilidade. A escola já formou 11 turmas de 2010 a 2019, totalizando um número de 176 egressos, que estão presentes nas universidades, atuando no mercado de trabalho ou empreendendo em suas comunidades de origem. Em 2018, tivemos pela primeira vez, duas turmas de concludentes, uma de 4 anos e outra de 3 anos, de acordo com as novas resoluções dos cursos técnicos.

A Pedagogia da Alternância e o público-alvo dessa modalidade são jovens e adolescentes do campo, que estão aptos a estudar no Ensino Médio. Essa metodologia de ensino também pode ser aplicada no Ensino Fundamental, mas na região, a Pedagogia da Alternância foi implantada apenas no Ensino Médio das EFAs, sendo utilizada também, em outras escolas profissionalizantes e recentemente na Universidade Federal do Piauí (UFPI) no Curso de Licenciatura e Educação do Campo (LEdoC). O que se percebe, em especial, nas EFAs, é que essa Pedagogia é vivenciada com mais afinco, sendo fiel aos princípios e finalidades que a diferenciam de outras formas de ensino.

Em setembro 2012 foi implantado na escola a I FEIRA AGROPEC EFAEM. Nesse evento, aconteceu a demonstração da cultura local, com apresentações teatrais e de cantores da terra, produtos da agricultura camponesa, através da exposição dos mesmos e seu beneficiamento, amostragem e venda de hortaliças, exposição de produção animal da região, artesanato, comidas típicas. Buscou-se reunir a diversidade e as riquezas regionais, valorizando o desenvolvimento local.

A feira acabou virando tradição, tornou-se um momento de reafirmação de identidades, possibilitando encontros entre amigos, confraternização entre as famílias vindas de várias localidades para prestigiarem as apresentações e os trabalhos realizados por seus filhos. O evento é aberto para toda comunidade. Os recursos arrecadados servem para sanar algumas despesas da escola ao longo do ano. É um momento muito rico, de fortalecimento de vínculos e reconhecimento de identidades.

Figura 04: III FEIRA AGROPEC equipe de Produção Animal 


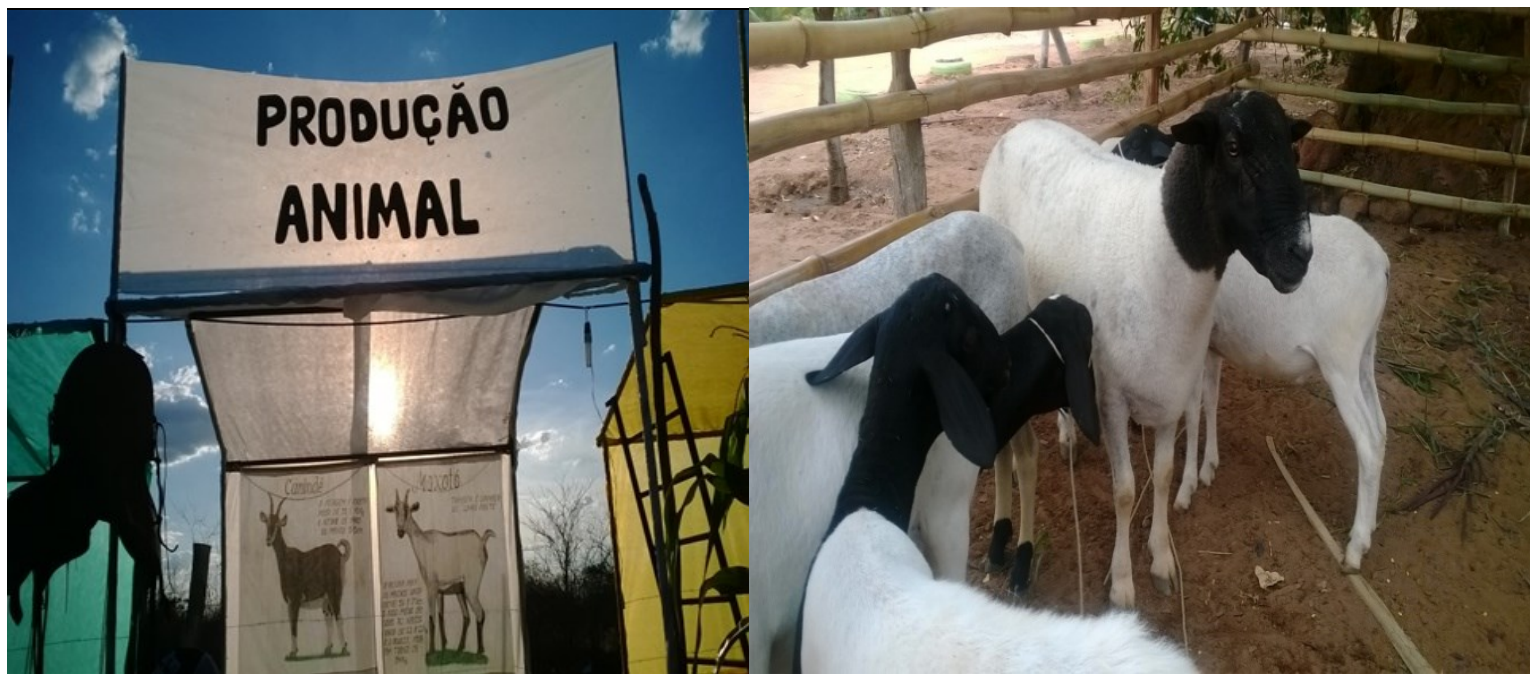

Fonte: Acervo fotográfico da EFAEM - ano 2014

Ao longo da caminhada da EFA, aconteceram avanços positivos, que evidenciou ainda mais a importância do trabalho realizado por essa instituição de ensino. A EFAEM não tem o objetivo de formar apenas técnicos, mas sim, cidadãos, famílias. Buscando sempre parcerias, estabelecendo relações de respeito e confiança com seus colaboradores e a região onde está localizada. Através de cursos, oficinas, palestras leva-se até as famílias, novos conhecimentos por meio da participação do aluno ou de seus pais, que se dão pelas ações do Serviço Nacional de Aprendizagem Rural (SENAR), Serviço Brasileiro de Apoio às Micro e Pequenas Empresas (SEBRAE), Empresa Brasileira de Pesquisa Agropecuária (EMBRAPA), Sindicato dos Trabalhadores Rurais (STR), Universidade Federal do Piauí (UFPI) e muitos outros órgãos ou entidades, que, direta ou indiretamente, fazem parte do processo formativo dos educandos.

A EFAEM possui relações sólidas com essas instituições. Uma que queremos destacar foi o engajamento com a UFPI, Campus Cinobelina Elvas, em Bom Jesus (PI). Esse vínculo teve início em 2013, com a visita do professor de Extensão Rural, Janailton Coutinho à escola. O docente já realizava um trabalho de extensão em outra EFA, e, a partir daí, começou a dialogar com a EFAEM, passando a desenvolver algumas práticas na instituição, juntamente com o grupo de alunos dos cursos de Veterinária, Agronomia, Zootecnia e Engenharia Florestal.

Os universitários faziam as visitas com frequência à escola e a parceria foi se consolidando. Dessa parceria surgiram novas possibilidades, dando-nos novas perspectivas de ensino e aprendizagem, até o momento da implantação do curso de Licenciatura em Educação do Campo (LEdoC) na região, quando fomos ainda mais impulsionados a fazer parte das discussões e reflexões a respeito da Educação do Campo.

Na primeira turma da LEdoC, em 2014, contou com o ingresso de quatro monitores da equipe, que, na época, era composta de 12 pessoas, permitindo que nos inserirmos em outros 
espaços de instrução e experiências, em busca de novas alternativas que viessem a atender as especificidades dessa metodologia de ensino diferenciada.

Com a inserção da Universidade na escola, foi possível levar mais adiante o trabalho realizado pela EFA, por meio do estímulo de ingresso dos alunos egressos na universidade. Parte desse incentivo veio de outras formas de relação que a universidade estabeleceu com a EFAEM, através da participação em Cafés com Segurança (que são espaços de diálogo e trocas de saberes e experiências), viagens, Dia de Campo, Formação de Monitores e nos cursos oferecidos principalmente no Curso de Licenciatura em Educação do Campo. Outra forma de contato da Universidade com as comunidades da região foi por meio dos trabalhos realizados pelos monitores da EFAEM na LEdoC. Dessa forma, houve a parceria com a Comunidade Chupeiro, zona rural de Eliseu Martins (PI).

Essa experiência está cada vez aumentando o número de professores engajados e motivados a vivenciar outras realidades. Uma das parcerias mais recentes entre Universidade e a escola, tem se dado por meio das ações do Núcleo de Agroecologia do Vale do Gurguéia (NAGU), que representa um ponto comum de trabalho conjunto UFPI, EFAEM e Comunidade Chupeiro, envolvendo alunos, professores e comunidade.

\section{RECONSTITUIÇÃO DA HISTÓRIA E DA MEMÓRIA DA EFAEM}

A reconstituição de acontecimentos vividos pode contribuir para transformá-los em acontecimentos lembrados, que podem vir à tona, através de narrativas que compõem a história da EFAEM, por exemplo.

Nesse aspecto, o trabalho de recordação da memória possibilita conhecer um pouco da trajetória, as dificuldades enfrentadas, as conquistas e as realizações, que abrem espaço para o conhecimento através da rememoração das histórias daqueles que contribuíram diretamente com o processo histórico da EFAEM, tais como: João Emílio Lemos Pinheiro, Adriana Moura, Maria José Ferreira de Sousa, Eliseu Rodrigues Machado, Osvando Barbosa de Lima. Nomes que vão desde mães de ex-alunos, educadores e lideranças locais e regionais que representam as associações, sindicatos, igrejas e famílias. Sabemos que existem tantos outros sujeitos que compuseram essa história e que não foram mencionados, mas não deixaram de serem importantes nesse processo de reconstituição da história e memória da EFA.

Segundo a professora Adriana Moura, primeira secretária da EFAEM:

Falar da Escola Familia Agrícola de Elisen Martins é falar de um projeto audacioso, inovador e transformador. Audacioso porque exigiria de nós gestão, secretariado, monitores, associação 
de pais e parceiros, principais mantenedores do projeto, disponibilidade e compromisso. Inovador por se tratar de uma realidade nova, diferente até então na área da educação daquela região e transformador porquê de fato mudaria o cotidiano das partes envolvidas, escola, aluno, comunidade e o meio ao qual estavam inseridos. (2018)

A professora Adriana relatou os fatos com muita propriedade. Ela foi uma referência para as famílias e continua sendo lembrada e respeitada até hoje, pela dedicação e comprometimento com as causas da escola. Dentro da EFAEM ela foi, para além da docência e gestão, mãe, psicóloga e amiga, deixando bons exemplos e entendimento da Pedagogia da Alternância.

Com as entrevistas, o ato de rememorar desenhou-se o retrato da recordação da história e da memória da EFAEM, possibilitando perceber como as lembranças e as experiências dos entrevistados permaneciam vivas e vibrantes. Por meio dessas narrativas, percebeu-se uma interação singular do comprometimento dos entrevistados com as questões relativas à escola.

Realizar a reconstituição de uma instituição como a EFAEM foi percorrer caminhos que estão arraigados de valores, desafios e conquistas. De acordo com Pollak (1992, p. 204):

A memória é um elemento constituinte do sentimento de identidade, tanto individual como coletiva, na medida em que ela é também um fator extremamente importante do sentimento de continuidade e de coerência de uma pessoa ou de um grupo em sua reconstrução de si.

Reconstruir a história da EFAEM fundamenta e materializa a memória dessa instituição tão importante. Sua implantação favoreceu o desenvolvimento local, através da participação das famílias. Um projeto dessa natureza promove uma organização social, a partir do capital humano e da valorização dos recursos naturais. $\mathrm{Na}$ fala de João Emílio foi visível reconhecer suas contribuições. Os relatos de experiências trazidas por ele foram fundamentais para o momento de edificação da escola, para além da sua vasta experiência na Pedagogia da Alternância.

Maria José Ferreira de Sousa (2018), uma liderança da Igreja Católica, disse: “o entusiasmo das pessoas que participaram das reuniões para implantação da escola era muito grande". Recorda também, que o Pe. Cícero sempre foi muito empenhado. Mesmo em meio às dificuldades enfrentadas, a escola recebeu muito apoio e colaboração, não só de moradores da cidade, mas também, da região, que assim que a escola passou a funcionar, colocaram seus filhos para estudarem na mesma. Outra liderança religiosa é a D. Maria José Ferreira de Sousa, mais conhecida como D. Mazé, essa figura traz contribuições para a escola desde sua fundação.

Segundo Bosi (1987), a lembrança é a história da pessoa, enquanto vivenciada, é a sobrevivência do passado. A construção social da memória é um fenômeno que nos acompanha por toda a vida. Portanto, lembrar é voltar ao passado, possibilitando um despertar da história. 
Eliseu Rodrigues Machado, agricultor, responsável pela obra de construção da escola e membro da associação nos esclarece:

Eu desejei tanto ver o camponês ser valorizado, lembrado. Quando surge o projeto de implantação da EFAEM meu sonho se realizou. Esta escola surge como um apoio para os agricultores. O Padre Cicero contribuiu bastante para a construção e desenvolvimento da escola e também preparou pessoas para assumir este compromisso, o monitor Osvando é fruto do trabalho de dedicação do Padre Cícero é tão tal que quando o padre foi transferido para outro município quem ficou à frente da escola foi o Osvando dando continuidade aos seus ensinamentos e não o decepcionou. (2018)

O Sr. Eliseu emocionou-se muito ao rememorar lembranças tão significativas de sua ligação com a história da escola. Eliseu Machado, como é conhecido, nunca teve um filho estudando na EFA, mas isso não o fez menos comprometido, sempre foi e é muito dedicado a tudo que está relacionado à escola. É importante perceber o grau de envolvimento dessas pessoas com a escola. Outro exemplo é o da mãe de um ex-aluno que acrescenta:

Desde o início desta escola fiquei muito feliz, pois meu filho e os filhos de outros moradores de comunidades rurais tiveram oportunidade de estudar e conhecer as realidades as quais fazem parte. Esta escola deu um novo ânimo para as famílias da região. (2018)

A participação das famílias nesse processo de estruturação da escola foi fundamental. As mães, sobretudo, sentem-se representadas com a escola, veem na EFA um incentivo para a permanência de seus filhos do campo no campo.

Osvando Barbosa de Lima, monitor e diretor adjunto da EFAEM, também participou das primeiras discussões e acrescenta que:

Este projeto da EFA é um projeto almejado no amor, na vontade de ajudar o próximo, no desejo de promover uma ação que envolvesse os camponeses em um ensino que atendesse suas especificidades, que reafirmasse sua identidade. Enfatiza ainda que os monitores exercem papel importante neste processo de formação estimulando o protagonismo dos educandos. (2018)

O monitor Osvando participou das primeiras reuniões para implantação da escola. Ele foi quem dormiu a primeira noite com os alunos em 14 de abril de 2006. Em 2010, iniciou um trabalho diferenciado como monitor. Até 2012, exerceu a função de secretário da escola, adquirindo experiência com o Pe. Cícero. Passou, posteriormente, a direção. Atua junto às famílias através das reuniões, mutirões, assembleias e também, na formação integral dos alternantes.

João Emílio Lemos Pinheiro, ex-secretário executivo da AEFAPI, finaliza dizendo: 
Eu me sinto com a implantação da EFAEM como filho do Gurguéia, um filho dos brejos, filho do agricultor familiar, uma pessoa encantada com o campo, pois a escola projetada neste viés me arremete a minha família, pois sou filho da região e sai dai bem cedo. A Escola Família Agricola traz, um pouco de minha experiência, um pouco de esperança para essa região como também para outras localidades. Pois quando comecei a trabalhar com as EFAS só existia duas, agora já são dezessete, sei que eu e muitas pessoas contribuimos para o surgimento deste processo formativo. Sou satisfeito por ter contribuido com a construção da escola apoiando ao Padre Cícero que é uma grande liderança, fico tranquilo e realizado em saber que esta escola continua firme graça as pessoas que tem uma nova visão de educação que passa por um processo formativo, de participação, você mesma está nesta condição de protagonista e que vai continuar este trabalho, o Osvando foi fundamental com a saida do Padre Cicero, assumindo a parte pedagogia envolvendo as famílias tocando a escola para frete, assim como outros educadores. É importante dinamiz̧ar a educação da Região do Vale do Gurgueia. (2018)

Com essa constituição da história e da memória da EFAEM, evidenciamos que as informações documentais da escola dialogam com as histórias relatadas pelos entrevistados. A análise metodológica do processo histórico vivido, nos arremete muitas recordações, saberes, experiências, conhecimentos e uma compreensão da realidade. Ao confrontar os elementos desse trabalho, chega-se ao ponto de entendermos que existe uma ação-reflexão-ação que respondem ao vínculo que existe entre escola, família e comunidade, através de uma interação social dos sujeitos que compõe as especificidades da EFAEM.

\section{CONSIDERAÇÕES FINAIS}

Este trabalho estabeleceu uma relação de projeção da identidade, através da reconstituição da história e da memória da EFAEM. A questão de pertencimento e da identidade dos envolvidos foi percebida ao longo das entrevistas. Observamos que o vivido e os fatos históricos rememorados, representam a história de um passado, no sentido de reconstruir o que se transcorreu e dele lembrar no presente.

Sabemos que a EFA trouxe certo desenvolvimento para a região, dando um novo ânimo às famílias, enfatizando a importância do fortalecimento de uma educação que acontece em um viés inovador, sustentável e que agrega valores ao que é vivido nos espaços formativos. A memória da EFA é uma espécie de fonte de inspiração para os trabalhadores e trabalhadoras do campo, que acreditam nessa filosofia de ensino. Desse modo, compreendemos que a EFAEM no município e na região é bastante reconhecida, além de realizar um trabalho que fortalece as famílias camponesas da região do Vale do Gurguéia, no Estado do Piauí.

\section{REFERÊNCIAS}


ALBERTI, V. História oral: a experiência do CPDOC. Rio de Janeiro: Fundação Getúlio Vargas, 1990.

BENJAMIN, W. Magia e técnica, arte e política. São Paulo: Brasiliense, 1993.

BOSI, Ecléa. Memória e sociedade: lembranças de velhos. São Paulo: T. A. Queiroz Editor da Universidade de São Paulo, 1987.

CALDART, Roseli S. Por uma Educação do Campo. 3. ed. Petrópolis: Vozes, 2008.

DELGADO, Lucilia de Almeida Neves. História oral: memória, tempo, identidades. Belo Horizonte: Autêntico, 2006.

FENTRESS, James; WICKHAM, Chris. Memória social: novas perspectivas sobre o passado. Lisboa: Teorema, 1992.

FERRO, Maria do Amparo Borges. Educação e sociedade no Piauí republicano. Teresina: Fundação Cultural Monsenhor Chaves, 1996.

FREITAS, Sônia Maria de. História oral: possibilidades e procedimentos. São Paulo: Humanistas/FFLCH/USP: Imprensa Oficial do Estado, 2002.

GIMONET, Jean-Claude. Praticar e compreender a Pedagogia da Alternância dos CEFFAs. Petrópolis: Vozes, Paris: AIMFR, 2007.

MEIHY, J. C. S. B. Manual de história oral. São Paulo: Loyola, 2005.

MEIHY, J. C. S. B.; HOLANDA, F. História oral: como fazer, como pensar. São Paulo: Contexto, 2007.

NOSELLA, Paolo. Educação no Campo: origens da pedagogia da alternância no Brasil. Vitória: EDUFES, 2012.

PALITOT, Maria de Fátima de Souza. Pedagogia da Alternância: estudo exploratório na Escola Rural de Massaroca (ERUM). 2007. 100 f. Dissertação (Magister Scientiae) - Universidade Federal de Viçosa, Viçosa, 2007.

POLLAK, M. Memória e identidade social. Estudos históricos, Rio de Janeiro, APDOC, v. 5, n. 10, p. 200-215, 1992.

QUEIROZ, João Batista P. de. Construção das Escolas Famílias Agrícolas no Brasil: Ensino Médio e Educação Profissional. 2004. Tese (Doutorado em Sociologia) - Departamento de Sociologia. Universidade de Brasília, Brasília, 2004.

ROUSSO, H. A memória não é mais o que era. In: AMADO J. FERREIRA, M. de M. (Orgs.). Usos e abusos da História Oral. Rio de Janeiro: Fundação Getúlio Vargas, 1996. p. 93-102.

SILVA, Maria do Socorro. A Formação Integral do Ser Humano: referência e desafio da Educação do Campo. Revista Formação por Alternância, Brasília: União Nacional das Escolas Famílias Agrícolas do Brasil, v. 1, n. 5, ano 3, p. 45-61, 2007. 
SILVA, Maria do Amparo Holanda da. História e memória das primeiras instituições escolares de José de Freitas-PI (1928-1971). 2012. Dissertação (Mestrado em Educação) Centro de Ciências da Educação. Universidade Federal do Piauí, Teresina, 2012.

THOMPSON, P. A voz do passado: história oral. 3. ed. Rio de Janeiro: Paz e Terra, 1992. 